\title{
Cascaded Boost AC-AC Converter with High-Gain Voltage
}

\author{
Azza E. Lashine ${ }^{1}$, Sayed M. Ahmed ${ }^{2 *}$, and Dina S. M. Osheba ${ }^{1}$ \\ ${ }^{l}$ Department of Electrical Eng., Shebin el kom Faculty of Eng., Menoufia University, Cairo, Egypt. \\ ${ }^{2}$ Department of Industrial Technology, Faculty of Technological Industry and Energy., \\ Delta Technological University, Quesna, Egypt. \\ (Corresponding author: Eng.sayed1979@yahoo.com)
}

\begin{abstract}
This paper presents cascaded boost AC-AC converter with control strategy. The proposed system can attain high-gain voltage by using low-voltage rating switch devices. The control technique leads to nearly unity power factor and the required high voltage at stop working unit (SWU). The output voltage can be controlled up to double the input voltage multiplied by the number of units. The proposed converter has many advantages such as, low number of semiconductor switches, nearly sinusoidal output voltage, and negligible distortion in the supply current and load voltage waveforms. The proposed cascaded converter is suitable to be extended because all the AC - AC converter units have similar construction, control strategy, and operating conditions. Accordingly, maintenance is simple and the defective unit can be easily detected and compensated. The prototype converter with several numbers of units is constructed and tested to verify the performance. The proposed circuit and control technique is validated by the simulation results with MATLAB software.
\end{abstract}

Keywords: AC-AC Converter, Cascaded Converters, Boost AC to AC.

\section{Introduction}

AC-AC Converter has been widely used to obtain both AC voltage and frequency controlled or one of them according to the requirement of the load. They are used in many industrial applications such as lighting control, starting and speed control of the motor [1]. The AC/AC converters are divided into two main types:

- Indirect AC converter which utilizes a DC link between AC supply and load.

- Direct AC converter that provides direct conversion.

Indirect AC converters are complicated and have high conversion losses, therefore give rise to poor proficiency. Their dependability is ditto low, because of a middle DC interface capacitor [2]. In direct ACAC converters [3-5], the variable output voltage and the frequency are obtained through a single stage power conversion [6-7]. These can be implemented as AC voltage controllers and direct frequency changers (DFC). They offer many advantages, such as simple circuit implementation, easier control, small size, and low price.

The single-phase boost $\mathrm{AC}-\mathrm{AC}$ converter is depicted in Figure (1). It uses two bidirectional switches and one inductor. It has a simple structure and produces an output voltage more than the input voltage.

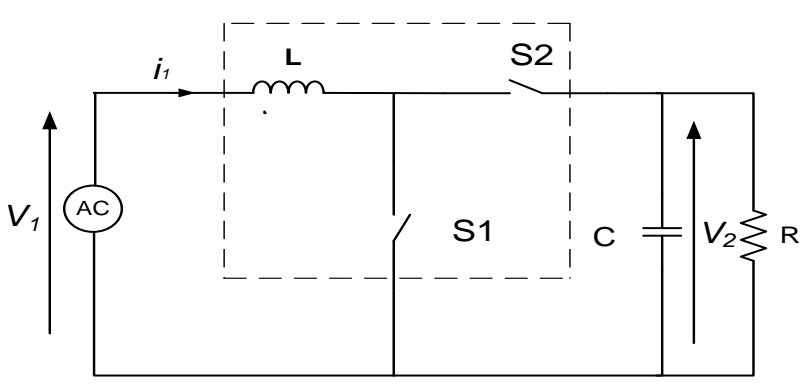

Figure 1- Single - Phase AC-AC boost converter

Cascaded AC-AC converters are widely used in high voltage and high power applications [8-9]. Its converters have been considered as a viable solution for high voltage applications. The attractive features of multilevel converters are as follows:

1) Cascaded converters can easily work at medium and high voltage.

2) Can be obtained high-gain output voltages using low-voltage rating switch devices.

3) They can operate at low switching frequencies

4) Can produce output voltages with low distortion.

5) Allow for high quality output voltages and input currents. 
Because of this features the cascaded converters have been recognized as attractive solutions for high- gain voltage direct-current transmission, solid state transformers (SST) and photovoltaic (PV) systems. In this paper, a proposed converter in this paper features a different series connection concept, the cascading, which has separate AC power supplies for each unit and can be extended for $\mathrm{n}$ unit to achieve high voltage. The presented system is to improve the cascaded boost AC - AC converter with the simplicity of structure and control and high voltage by using standard low-voltage rating semiconductor devices. Study of proposed system, theoretical, and mathematical analysis are discussed. The principle of operation and control of the converter are presented. A prototype of high-gain cascaded AC - AC converter is constructed for the simulation studies.

\section{System Description}

\subsection{Power Circuit}

Figure (2) shows a cascaded AC-AC boost type voltage regulator. Boost $\mathrm{AC}-\mathrm{AC}$ converter consists of two bi-directional switches $(\mathrm{S} 1, \mathrm{~S} 2)$ are used in this circuit as shows in Figure (1). An input boost inductor $\left(\mathrm{L}_{\mathrm{s} 1}\right)$ is located between the ac source and the switch S1. Can use more boost ac-ac converter in series to achieve high- gain voltage.

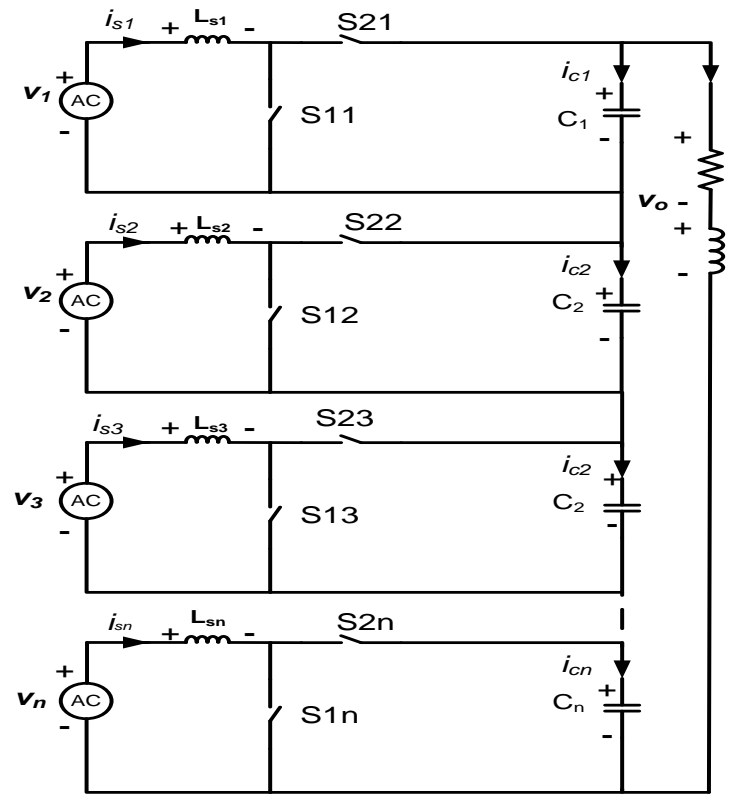

Figure 2- Proposed cascaded boost ac-ac converter unit

\subsection{Control Circuit}

In figure (3), the voltage reference signal $\mathrm{V}_{\text {ref }}$, is select according to the required load voltage. This value divided on number of units and compared with the reference voltage signal. The error signal is passed through a Proportional Integral (PI) controller.
The controller output is then multiplied by the input voltages $\mathrm{v}_{1}$, to produce the command currents is ref $_{\text {ref }}$ for one unit. The supply currents $i_{s 1}$ are compared with their corresponding command and the errors is processed through hysteresis controller to produce the signal pulse for S11. The signal pulse is processed through logic NOT gate to produce the signal pulse for S21. The first unit signals can be used for the rest of the units due to its similar structures with the other units. So that, the output of the hysteresis controller is used signal pulse for S1n and output NOT gat is used signal pulse for S2n. This control strategy ensures that the load voltage is kept at voltage reference.

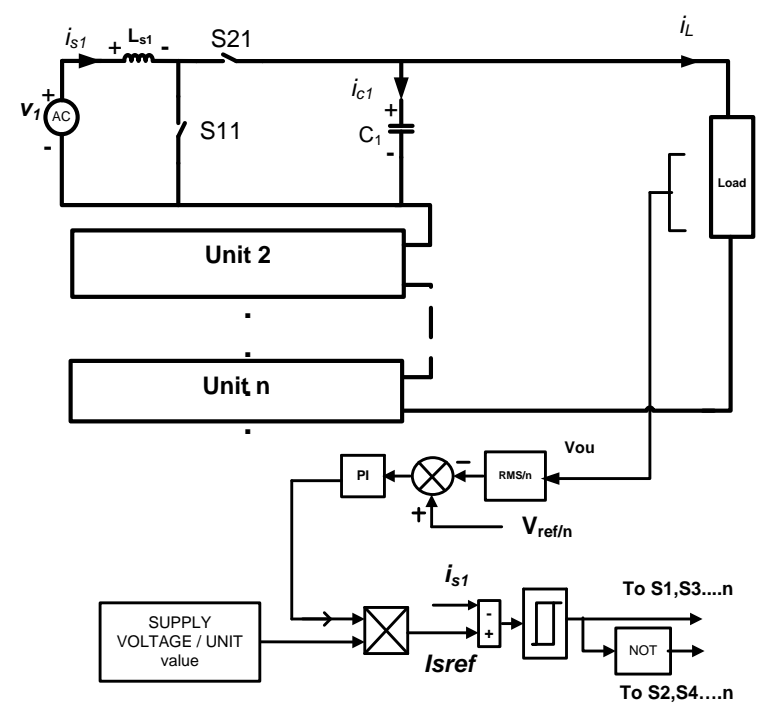

Figure 3- Block diagram of the Proposed Control

\subsection{Operation Modes}

$$
\text { Strategy }
$$

The cascaded boost ac-ac converter shown in Figure (2) has two modes of operations;

Mode 1: In this mode, the switches S1n are turned OFF and switches S2n are turned ON. The current supply decreases and the energy stored in each capacitor are charged from each unit. This mode continuous until the supply currents isl decrease to be less than or equal to [(is ref $\left.)-0.5^{*} \mathrm{H}\right]$.

Where: $\mathrm{H}$ is the hysteresis band. is $\mathrm{ref}_{\mathrm{ref}}$ is the command current.

Mode 2: In this mode, the switches S1n are turned $\mathrm{ON}$ and switches S2n are turned OFF. The load is supplied from sum energy stored in each capacitor and the supply current is 1 is increase less than or equal to $\left[\left(\mathrm{is}_{\mathrm{ref}}\right)+0.5 * \mathrm{H}\right]$. 


\section{Mathematical Analysis}

For the two modes of operations the following equations can be deduced:

Mode 1: Power switch S2n is turned ON and power switch $\mathrm{S} 1 \mathrm{n}$ is turned OFF.

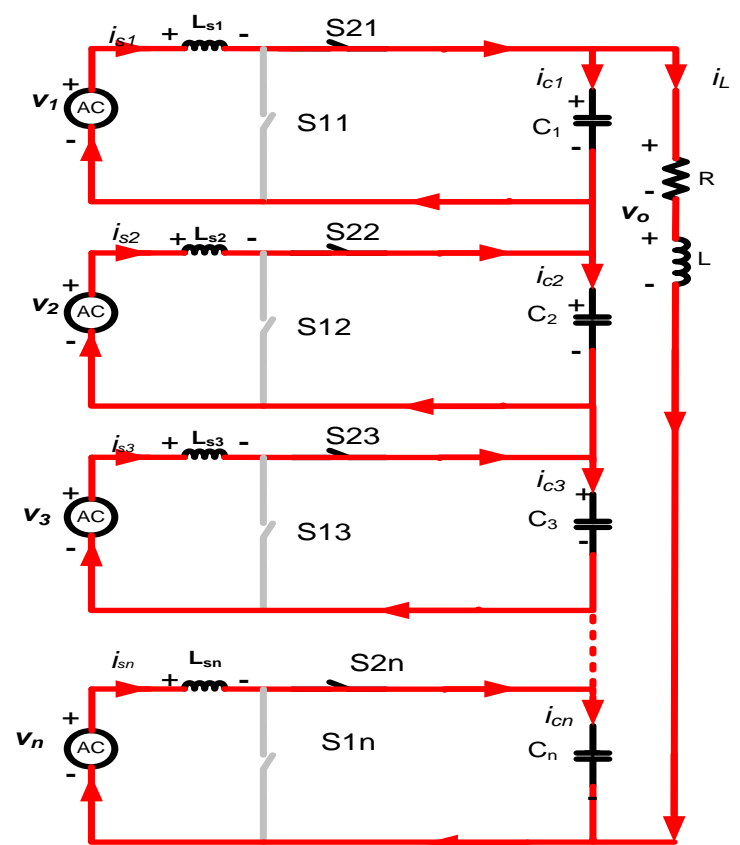

Figure 4- Equivalent circuit for mode1

$v_{1}=\mathbf{V m} \sin (\omega t)$

$v_{1}=v_{2}=v_{3} \cdots v_{n}$

$v_{1}+v_{2}+\cdots v_{n}=\frac{d i_{s 1}}{d t}\left(L_{s 1}+L_{s 2}+\cdots L_{s n}\right)+i_{L} R+L \frac{d i_{L}}{d t}$

$v_{c 1}=\frac{1}{C_{1}} \int i_{c 1} d t+v_{c 10}=v_{1}+\frac{d i_{s 1}}{d t} L_{s 1}$

$v_{c 2}=\frac{1}{C_{2}} \int i_{c 2} d t+v_{c 2 O}=v_{2}+\frac{d i_{s 2}}{d t} L_{s 2}$

$v_{c n}=\frac{1}{C_{n}} \int i_{c n} d t+v_{c n o}=v_{n}+\frac{d i_{s n}}{d t} L_{s n}$

$i_{s 1}=i_{s 2}=i_{s 3} \ldots i_{s n}$

Where $\mathbf{V m}$ is the peak voltages, $\omega$ is the angular frequency of the voltages.

Mode 2: the odd no. power switch S2n is turned OFF and. power switch $\mathrm{S} 1 \mathrm{n}$ is turned $\mathrm{ON}$.

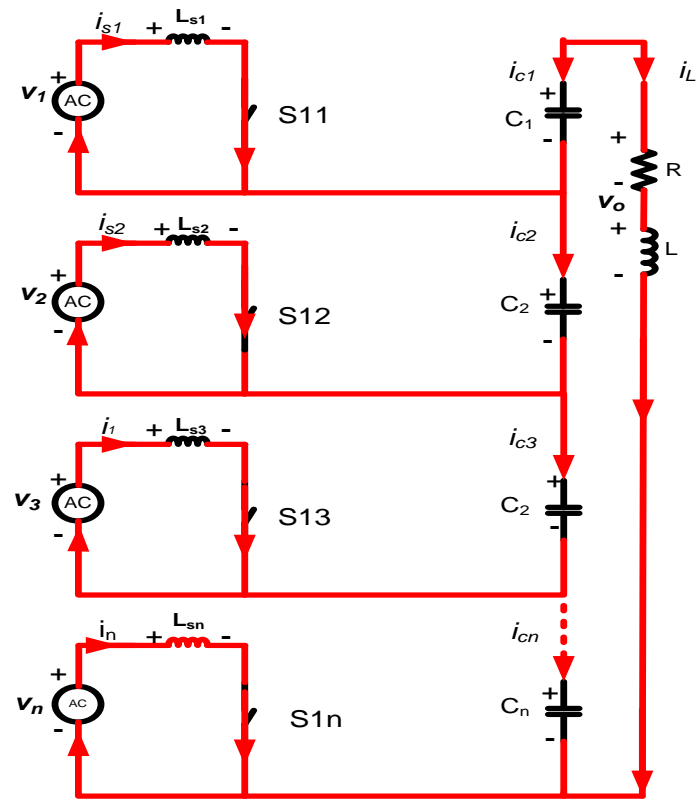

Figure 5- Equivalent circuit for mode2

$$
\begin{aligned}
& v_{n}=\frac{d i_{s n}}{d t} L_{s n} \\
& v_{c 1}=v_{c 2}=v_{c 3} \ldots v_{c n} \\
& v_{c 1}+v_{c 2}+\cdots v_{c n}=i_{L} R+L \frac{d i_{L}}{d t} \\
& i_{c 1}=i_{c 2}=i_{c 3} \ldots i_{c n}=-i_{L}
\end{aligned}
$$

\section{Simulation Results}

The simulation results are executed for the proposed system by MATLAB software. The simulation results for the proposed method are taken with the following specifications;

$v_{1}=v_{2}=v_{3}=v_{\mathrm{n}}=220 \mathrm{~V}, \mathrm{Ls}_{1}=\mathrm{Ls}_{2}=\mathrm{Ls}_{3}=\mathrm{Ls}_{\mathrm{n}}=20 \mathrm{mH}$

$\mathrm{C}_{1=} \mathrm{C}_{2}=\mathrm{C}_{3}=\mathrm{C}_{\mathrm{n}}=15 \mu \mathrm{f}$

Load side; is $\mathrm{R}=150 \Omega$ and $\mathrm{L}=250 \mathrm{mH}$.

The steady-state results of the proposed cascaded boost ac-ac converter using two units at reference voltage $700 \mathrm{~V}$ are shown in Fig.6. Figure 6.a shows the supply voltage (v1) and current (is1). It is clear that the input current is sinusoidal and in phase with the supply voltage so, the supply has a nearly unity power factor. From Fig.6.d, it is clear that, the RMS load voltage is equal to the reference voltage. Figure 6.c shows the sinusoidal load voltage. The output voltage for one unit is sine wave as shown in Figure (6.d). 


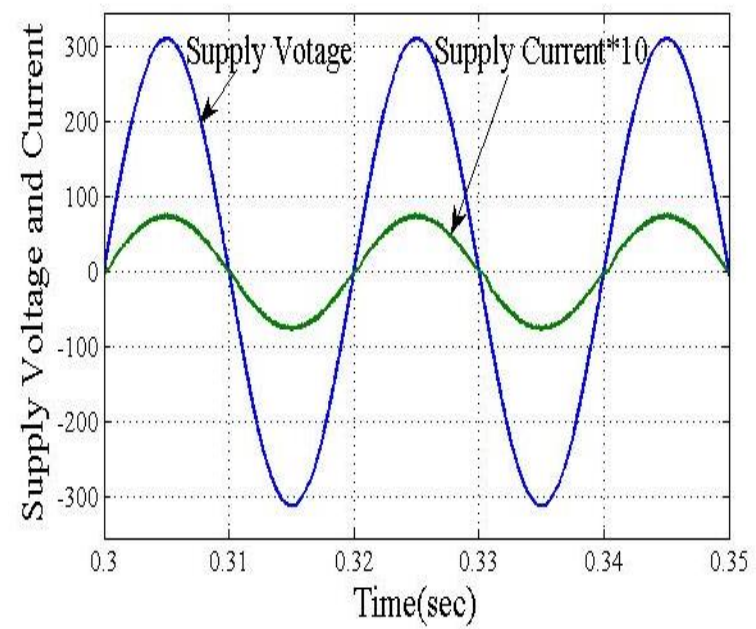

(a)

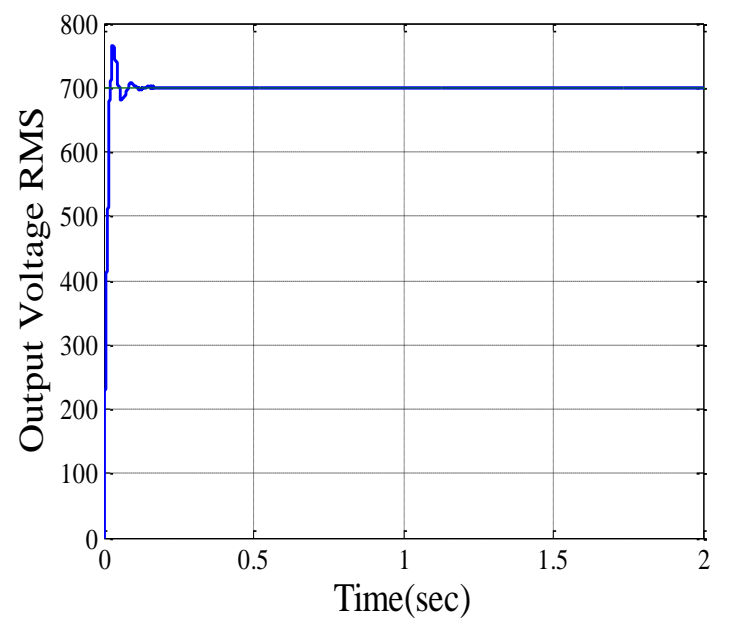

(b)

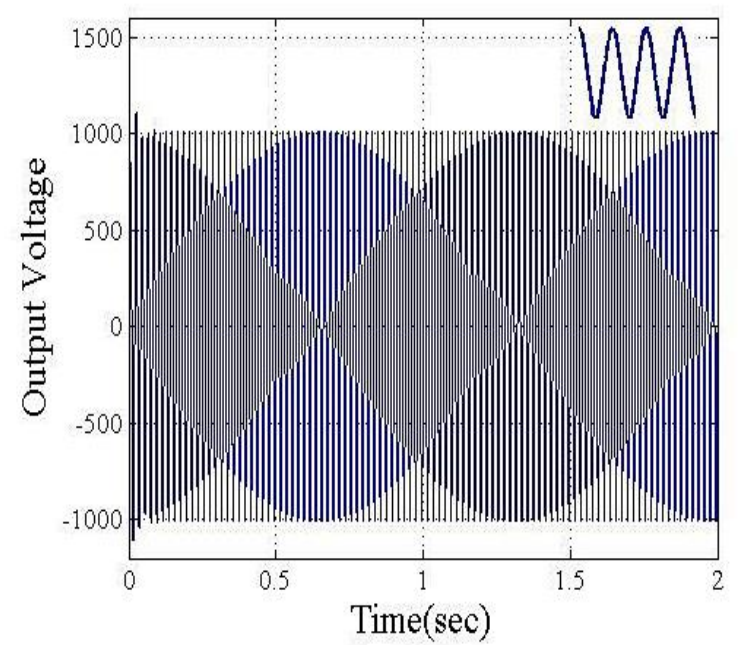

(c)

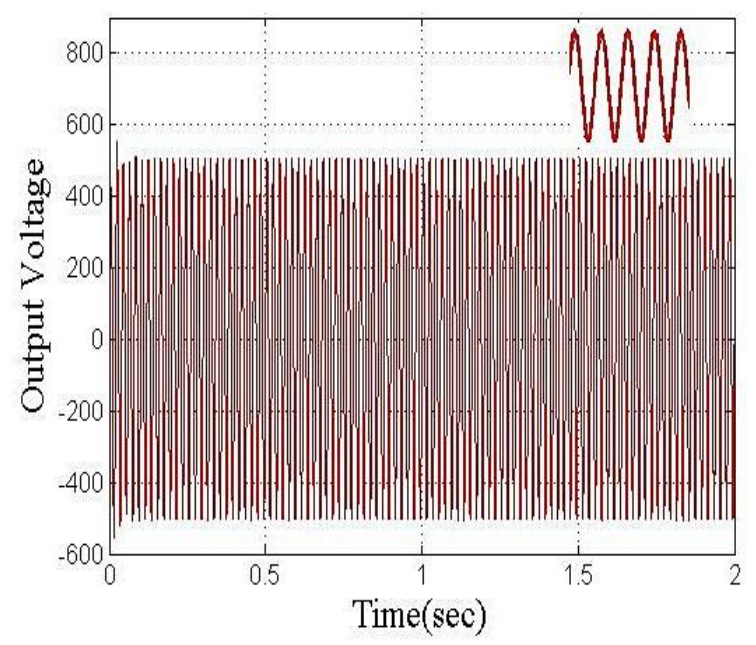

(d)

Figure 6- The steady state simulation results of proposed system; a) supply voltage and current; b) RMS load voltage; c) single phase load voltage d) output voltage of one unit

The change of load voltage due to change in the reference voltage from 700 to 800 are shown in Fig7. Fig.7.a. shows the response of the RMS value of the load voltage during the change of the reference voltage. Figure $7 . b$ shows the load voltage and its change during step change in reference voltage. The load voltage is nearly sine wave. Figure 7.c shows the output voltage of one unit, the figure indicate the change of step output voltage during the change in the reference voltage.

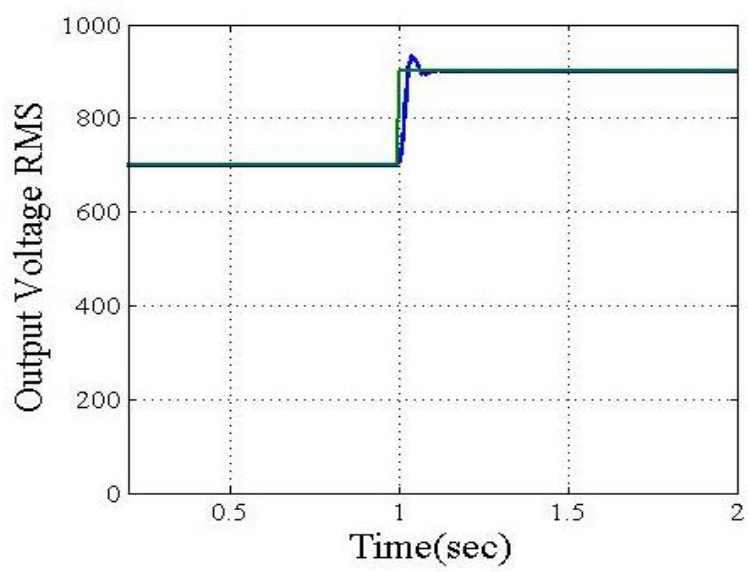

(a) 


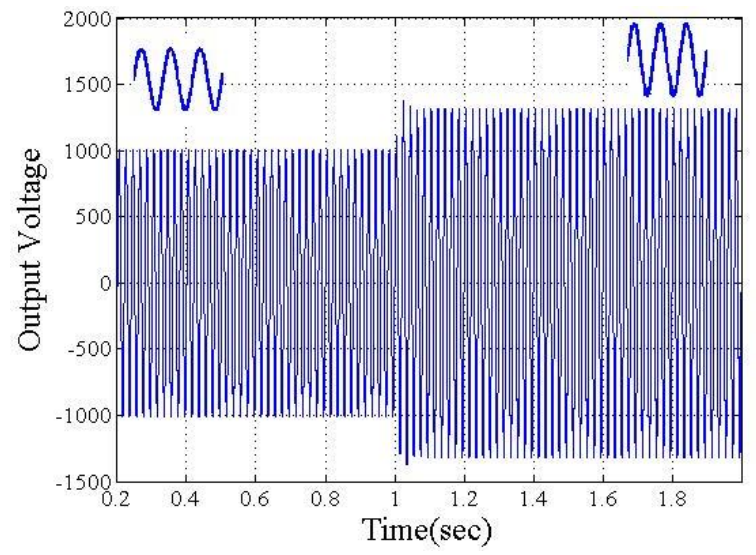

(b)

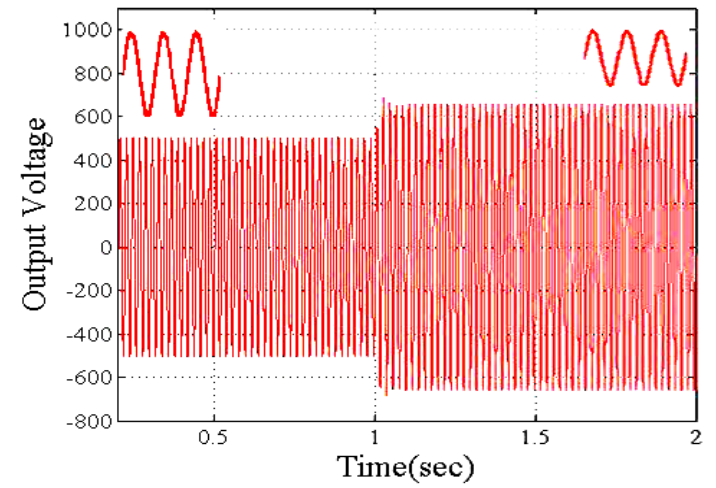

(c)

Figure 7- The transient state simulation results (the step change in reference voltage); a) RMS load voltage; b) the load voltage; c) output voltage of one unit

Figure 8 shows the responses of the system consist of four units due to a stop working in one unit. Fig.8.a. shows how the control system maintains constant load voltage with a problem occurs in the unit. From Fig.8.b, It is clear that the load voltage is sinusoidal with stop working in one unit. Figure 8.c shows the change of the output voltage of one unit to keep the load voltage constant. The output voltage of stop working unit is shown in Fig.8.d.

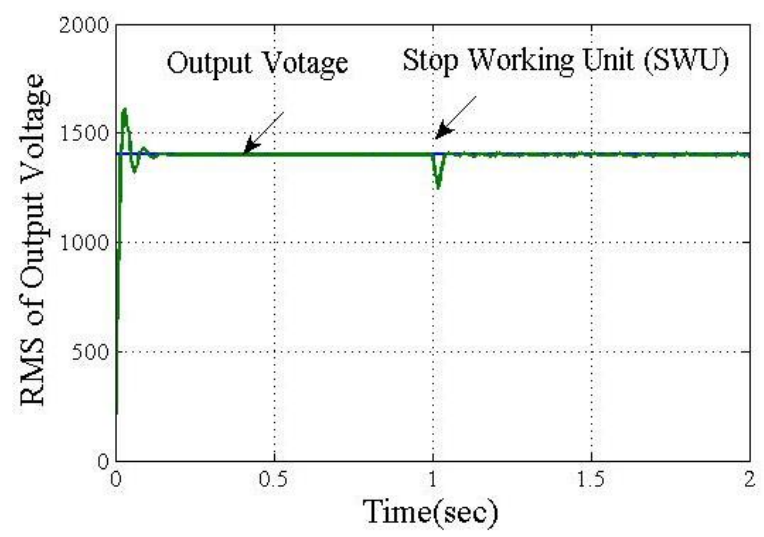

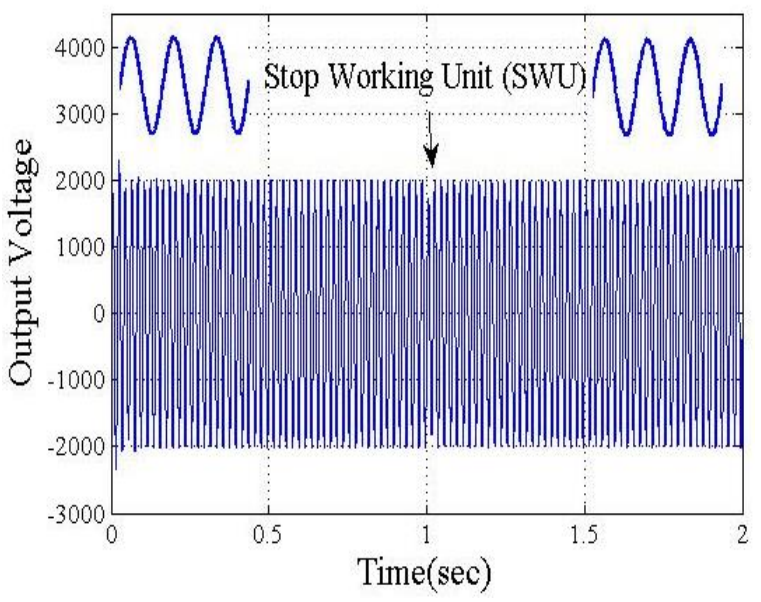

(b)

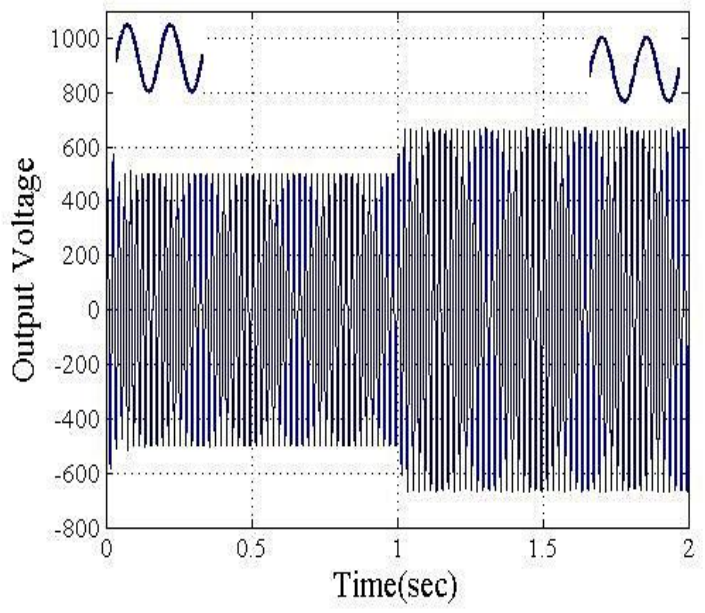

(c)

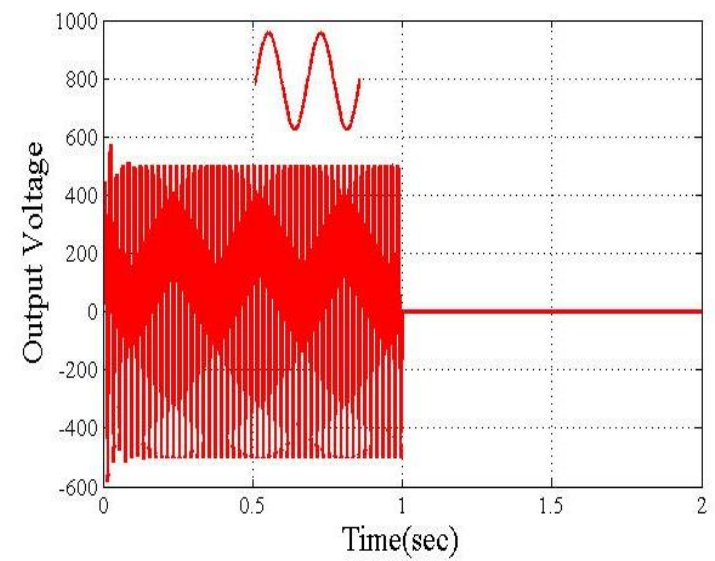

(d)

Figure 8- The transient state simulation results with bypass on the one unit; a) RMS of output voltage; b) wave farm of load voltage; c) output voltage of one unit; d) output voltage of stop working unit (SWU)

(a) 


\section{Conclusions}

A high-gain AC-AC boost converter with control technique has been presented in this paper. Mathematical analysis, control circuit and modeling of the circuit during the operation modes have been carried out. It can be concluded, the presented circuit yields high-gain $\mathrm{AC}$ voltage, reduction in the number of power switches. Simulation results show the effectiveness and validity of the proposed circuit. Transient response of the circuit has been tested and fast dynamic response has been achieved. The proposed system is effective to deal with faults in one of the units with fast compensation of the voltage. Supply currents are continuous, sine wave with nearly unity power factor.

\section{References}

[1] O. Ursaru, M. Lucanu, C. Aghion, N. Lucanu," Single-Phase Direct Boost AC-AC Converter", Advances in Electrical and Computer Engineering, Vol: 17, No: 4, 2017

[2] J. W. Kolar, T, Friedli, J. Rodriguez, P. W. Wheeler, "Review of Three-Phase PWM ACAC Converter Topologies", IEEE Transactions on Industrial Electronics, Vol: 58 , No: 11, PP: 4988 - 5006, Nov. 2011

[3] D. C. Lee, Y. S. Kim, "Control of Single-Phaseto-Three-Phase AC/DC/AC PWM Converters for Induction Motor Drives", IEEE Transactions on Industrial Electronics, Vol: 54 , No: 2, PP: 797 - 804, April 2007.
[4] E. C. Santos, C. B. Jacobina, N. Rocha, E. R. C. da Silva, "Six-Phase Machine Drive System with Reversible Parallel AC-DC-AC Converters", IEEE Transactions on Industrial Electronics, Vol: 58 , No: 5 , PP: 2049 - 2053, May 2011.

[5] P. Alemi, Y. C. Jeung, D. C Lee, " DC-Link Capacitance Minimization in T-Type ThreeLevel AC/DC/AC PWM Converters" IEEE Transactions on Industrial Electronics, Vol: 62 , No: 3 , PP: 1382 - 1391, March 2015

[6] 6. Fang, X.P.; Qian, Z.M.; Peng, F.Z. Singlephase Z-source PWM AC-AC converters. IEEE Power Electron. Lett. 2005, 3, 121-124. [CrossRef]

[7] Nguyen, M.K.; Jung, Y.G.; Lim, Y.C. SinglePhase AC-AC Converter Based on Quasi-ZSource Topology.

[8] G. Manasa, Ch. Santosh Kumar, Dr. D. Padmavathi," 4-Unit Cascade Dual Buck Inverter Using Control Systems", IOSR Journal of Electrical and Electronics Engineering, Vol: 9, No: 5, PP 87-105, (Sep - Oct. 2014)

[9] M. P. Kumar, G.R. Sri, K. Anurag, V. Sunny, O.Vijay, A. R. kumar," A Survey on Cascade Dual Buck Inverter with Phase-Shift Control", International Journal of Engineering Science and Computing, Vol: 7, No: 3, PP: 5713- 5720, March 2017 